\title{
The skinny on tuna fat: health implications
}

\author{
Asim Magbool ${ }^{1, *}$, Birgitta Strandvik ${ }^{2,3}$ and Virginia A Stallings ${ }^{1}$ \\ 'Department of Pediatrics, Division of Gastroenterology, Hepatology, and Nutrition, The Children's Hospital of \\ Philadelphia, University of Pennsylvania School of Medicine, 34th and Civic Center Boulevard, Philadelphia, \\ PA 19104, USA: ${ }^{2}$ Department of Pediatrics, Institute of Clinical Sciences, Göteborg University, Göteborg, \\ Sweden: ${ }^{3}$ Department of Biosciences and Nutrition, Karolinska Institute, NOVUM, Stockholm, Sweden
}

Submitted 24 February 2010: Accepted 8 December 2010: First published online 16 February 2011

\begin{abstract}
Objective: Dietary n-3 (omega-3) and n-6 (omega-6) PUFA have significant implications in health and disease prevention. Marine life is rich in long-chain $n-3$ PUFA. Children and adults in North America are reluctant fish eaters; canned tuna is a common fish in children's diets. Although a multitude of tuna products are available, their respective PUFA contents have not been well described. The aim of the present study was to compare the fatty acid (FA) profiles of different commercially available US tuna products.

Design: Fat and FA composition of eight products randomly selected from two US suppliers were analysed with capillary GC after lipid extraction.

Setting: Large north-eastern US grocery store chain.

Subjects: Canned tuna.

Results: Energy from fat varied from 3 to $33 \%$ and the essential FA (EFA) linoleic acid (18:2n-6) and $\alpha$-linolenic acid (18:3n-3) varied tenfold. DHA varied between 90 and $770 \mathrm{mg} / \mathrm{serving}$. The $n-6: n-3$ ratio was 3:1-4:1 in oil-packaged products, 2:1-7:1 in packaged tuna salads and 1:3-1:7 in water-packaged products. A similar magnitude of differences was seen in the ratio between arachidonic acid (20:4n-6) and DHA.

Conclusions: Light tuna canned in water may be a better choice of providing $n-3$ PUFA to individuals in a healthy population, whereas oil-packaged products may be preferable for those individuals with a need for increased EFA, such as for patients with cystic fibrosis. Awareness regarding PUFA content may aid in consumer product choices and health-care provider advice.
\end{abstract}

Keywords $n-3$ fatty acids DHA

EPA

Chronic disease
The modern Western diet has been characterized by marked changes in PUFA content, with an increase in $n-6$ (omega-6) fatty acids (FA) coupled with a decrease in $n-3$ (omega-3) FA. Lower intakes of the biologically important long-chain $n$-3 PUFA are observed in the modern Western diet as compared with the human diet from the huntergatherer periods and with traditional diets globally ${ }^{(1)}$. The observed lower intakes of $n-3$ PUFA and changes in dietary $n-6: n-3$ ratios have been implicated as a risk factor for common, chronic non-communicable conditions particularly for CVD, inflammatory bowel disease, obesity and diabetes ${ }^{(1,2)}$. The incidence and prevalence of these chronic diseases have increased in parallel to this specific aspect of the global nutritional transition in progress ${ }^{(1-5)}$. Fatty fish are a good source of long-chain $n-3$ FA, which are believed to have health benefits for the prevention and treatment of these non-communicable diseases. With disease prevention and risk reduction and key considerations, modifications of risk factors for these diseases need to be considered from childhood onwards. Children in North America in particular are reluctant fish eaters, with canned tuna being one of the most common types of fish consumed ${ }^{(6)}$. Although differences in PUFA profiles have been described for animal products by species and agricultural practices ${ }^{(7-10)}$, less is known about the PUFA characteristics of commercial tuna products. Consumers may consider all tuna products as being equally beneficial to human health, which may be inaccurate. The purpose of the present analysis was to describe the PUFA characteristics of some common commercially available products in order to increase awareness of potential product differences in the context of the diet and health of children and adults.

\section{Materials and methods}

Two cans each of eight commercially available US canned tuna products were obtained in duplicate from two of the three major US suppliers from a major north-east grocery store chain in November 2007. These included chunk white, light and albacore tuna varieties, packaged in either 
water or oil. Two tuna salad products (named 'regular' and 'fat free') were also obtained. The total fat content and FA composition of the canned contents (tuna products plus respective packaging medium - water or oil) were analysed by lipid extraction and analysis of FA methyl esters by capillary GC as described previously ${ }^{(7)}$. Each sample was analysed in duplicate, giving four analyses of each product, and the average values are reported. Serving size, total fat content and energy information were obtained from the respective Food and Drug Administration (FDA) Nutrition Facts labels. Complete FA profiles, including the $n$-3 FA $\alpha$-linolenic acid (ALA; $18: 3 n$-3), EPA (20:5n-3) and DHA (22:6n-3), as well as the $n-6$ FA linoleic acid (LA; 18:2n-6) and arachidonic acid (ARA; 20:4n-6), were expressed as $\mathrm{mg} / \mathrm{g}$ of the product and as per the manufacturer's suggested serving size.

\section{Results}

Serving sizes ranged from 56 to $82 \mathrm{~g}$. The total energy per serving ranged from $209 \mathrm{~kJ}(50 \mathrm{kcal})$ to $795 \mathrm{~kJ}$ ( $190 \mathrm{kcal})$. The percentage of energy from fat varied from 3 to 33 . The major fat classes and selected PUFA analysed are reported in Table 1 . The $n-6: n-3$ ratios ranged from $1: 3$ to 1:7 for tuna products in water, from 3:1 to 4:1 for products in oil and from $2: 1$ to $7: 1$ for the salad products. DHA content varied between 1.1 and $13.6 \mathrm{mg} / \mathrm{g}$ among the different tuna products (106 and $930 \mathrm{mg} / \mathrm{serving}$ ). As shown in Table 1 , the long-chain PUFA of the $n$ - 3 series $(\mathrm{EPA}+\mathrm{DHA}$ ) varied more than tenfold (per $\mathrm{mg} / \mathrm{g}$ ). The $n-6$ content also varied considerably across products, most likely related to the packaging medium (such as added vegetable oil), with a resulting ARA:DHA ratio varying between 1:1 and 1:9. The complete FA profiles for these different tuna products are presented in Table 2.

\section{Discussion}

In the present study, there was considerable variation across products with respect to PUFA profiles, DHA content and the $n-6: n-3$ ratio. LA $(18: 2 n-6)$ content $(\mathrm{mg} / \mathrm{g})$ was highest in the tuna salad, with a $>170$-fold difference between LA in the salad as compared with a chunk light product packaged in water. Tuna products packaged in water had higher EPA + DHA content and lower $n-6: n-3$ ratios as compared with tuna products packaged in oil. This may have significant implications for dietary counselling and consumer knowledge and choices in the context of health and disease.

Humans cannot synthesize essential FA (EFA) and are dependent on dietary sources to prevent deficiency. LA and ALA are the $n-6$ and $n-3$ EFA, respectively. Dietary EFA is enzymatically converted to longer-chain PUFA; ALA ( $n-3)$ is converted to EPA and DHA and LA (n-6) to ARA. These long-chain PUFA have many structural and functional roles throughout the life cycle via several well-described mechanisms, including effects on cell membrane fluidity, gene expression and modulation of the inflammatory response ${ }^{(11,12)}$

The Dietary Reference Intakes (DRI) for PUFA recommend dietary LA ( $n-6)$ and ALA ( $n-3)$ intakes specifically to meet adequacy and to prevent EFA deficiency in the general population ${ }^{(13)}$. The DRI further stipulates that up to $10 \%$ of the adequate intake for ALA can be in the form of DHA and EPA to support normal neural development and growth; this translates into 90-160 mg EPA + DHA/d for children aged $>4$ years ${ }^{(13)}$. Although ALA supplementation has been shown to increase red blood cell DHA content ${ }^{(14)}$, the conversion of ALA to long-chain PUFA is minimal, between $0.5 \%$ to DHA and $5 \%$ to $\mathrm{EPA}^{(15,16)}$. Therefore, the dietary intake of long-chain PUFA is an important determinant of serum and tissue PUFA status.

How much dietary $n$ - 3 PUFA intake is required to promote health and prevent disease is an important question. There are two components by which to address dietary $n-3$ PUFA: in relation to $n-6$ PUFA (the $n-6: n-3$ ratio) and as total $n$-3 PUFA (especially DHA + EPA). The epidemiological and anthropological data suggest increased risk of some chronic non-communicable diseases associated with changes of the $n-6: n-3$ ratio from historical and traditional diets to the modern Western diet; that is, from 1:1-1:2 to the current $15: 1-20: 1^{(1,4,17,18)}$. The $n-6: n-3$ PUFA ratio influences many key biological functions including the immune response and may be important in several chronic diseases. A dietary $n-6: n-3$ ratio of approximately $4: 1-5: 1$ may be desirable in this context ${ }^{(2,19)}$.

In terms of $n$ - 3 intake, DHA and EPA intake recommendations are available for pregnant women and lactating mothers to support normal neural growth, development and health in their offspring ${ }^{(20,21)}$. Currently, paediatric data regarding the impact of dietary $n-3$ PUFA as a preventive health strategy are not available to provide specific guidelines for children. However, the published recommendations for adults for both primary and secondary disease risk reduction are available and informative. Consensus committee statements regarding CVD and dyslipidaemia for adults published from the American Heart Association and other committees provide some guidance for children as well $^{(3,22)}$. The tuna PUFA profile data reported here are relevant in the consideration of food choices to promote $n$-3 FA intake and a favourable $n-6: n-3$ ratio.

Fish and seafood are rich in $n-3$ FA, particularly in long-chain $n$-3 FA (EPA and DHA) and have an $n-6: n-3$ ratio of $<1$. Fatty fish in particular are rich in long-chain $n-3$ PUFA. The nutrient composition of animals/animal products is influenced both during their life cycles and after they are killed and subsequently prepared/ processed for human consumption. Many studies have highlighted that the manner in which cultured fish and livestock are fed influences their total fat, PUFA profiles and pollutant content differently compared with their 
Table 1 Major fat and selected PUFA content and profiles of common available tuna products

\begin{tabular}{|c|c|c|c|c|c|c|c|c|c|c|c|c|c|c|c|c|}
\hline \multirow{4}{*}{ Medium } & \multicolumn{16}{|c|}{ Tuna product* } \\
\hline & \multicolumn{2}{|c|}{ Fat free } & \multicolumn{2}{|c|}{ Regular } & \multicolumn{2}{|c|}{ Chunk light } & \multicolumn{2}{|c|}{ Chunk light } & \multicolumn{2}{|c|}{ Chunk white albacore } & \multicolumn{2}{|c|}{ Chunk white albacore } & \multicolumn{2}{|c|}{ Solid white albacore } & \multicolumn{2}{|c|}{ Chunk light } \\
\hline & \multicolumn{2}{|c|}{ Saladt } & \multicolumn{2}{|c|}{ Salad $\ddagger$} & \multicolumn{2}{|c|}{ Water } & \multicolumn{2}{|c|}{ Water } & \multicolumn{2}{|c|}{ Water } & \multicolumn{2}{|c|}{ Water } & \multicolumn{2}{|c|}{ Oil } & \multicolumn{2}{|c|}{ Oil } \\
\hline & Mean & $\operatorname{sD} \S$ & Mean & $\operatorname{sD} \S$ & Mean & $\operatorname{SD} \S$ & Mean & SD§ & Mean & $\operatorname{sD} \S$ & Mean & $\operatorname{SD} \S$ & Mean & $\operatorname{sD} \S$ & Mean & $\operatorname{SD} \S$ \\
\hline Energy $(\mathrm{kcal}) \|$ & \multicolumn{2}{|c|}{70} & \multicolumn{2}{|c|}{190} & \multicolumn{2}{|c|}{60} & \multicolumn{2}{|c|}{50} & \multicolumn{2}{|c|}{60} & \multicolumn{2}{|c|}{70} & \multicolumn{2}{|c|}{90} & \multicolumn{2}{|c|}{90} \\
\hline Total fat (g/serving) & $6 \cdot 4$ & 0.0 & $27 \cdot 1$ & 0.2 & $1 \cdot 8$ & $0 \cdot 0$ & $1 \cdot 6$ & 0.0 & $2 \cdot 0$ & 0.0 & $1 \cdot 5$ & 0.0 & $3 \cdot 5$ & 0.0 & $2 \cdot 8$ & 0.0 \\
\hline Saturated fat (g/serving) & $1 \cdot 8$ & $0 \cdot 1$ & $4 \cdot 1$ & 0.0 & 0.5 & 0.0 & 0.5 & $0 \cdot 0$ & 0.5 & $0 \cdot 0$ & 0.4 & $0 \cdot 0$ & 0.6 & $0 \cdot 0$ & 0.5 & $0 \cdot 1$ \\
\hline Monounsaturated fat ( $\mathrm{g} /$ serving & $1 \cdot 2$ & $0 \cdot 1$ & $5 \cdot 5$ & 0.0 & 0.3 & 0.0 & 0.2 & 0.0 & 0.4 & $0 \cdot 0$ & 0.2 & $0 \cdot 0$ & 0.7 & $0 \cdot 0$ & 0.5 & $0 \cdot 0$ \\
\hline Polyunsaturated fat (g/serving) & $3 \cdot 4$ & $0 \cdot 1$ & $17 \cdot 5$ & 0.0 & 0.9 & 0.0 & 0.9 & 0.0 & $1 \cdot 1$ & $0 \cdot 0$ & $0 . \overline{9}$ & 0.0 & $2 \cdot 2$ & 0.0 & $1 \cdot 7$ & 0.0 \\
\hline \multicolumn{17}{|l|}{ Select PUFA } \\
\hline DHA (22:6n-3; mg/serving)* & $780 \cdot 0$ & $176 \cdot 0$ & $90 \cdot 2$ & $10 \cdot 7$ & $707 \cdot 8$ & $61 \cdot 6$ & $657 \cdot 4$ & $20 \cdot 2$ & $762 \cdot 2$ & $10 \cdot 6$ & $600 \cdot 3$ & $17 \cdot 4$ & $221 \cdot 8$ & $45 \cdot 4$ & $255 \cdot 9$ & $87 \cdot 4$ \\
\hline EPA $\left(20: 5 n-3 ; \mathrm{mg} /\right.$ serving) ${ }^{*}$ & $123 \cdot 0$ & $32 \cdot 8$ & $16 \cdot 4$ & 0.8 & $95 \cdot 2$ & $10 \cdot 1$ & $95 \cdot 8$ & $2 \cdot 2$ & $170 \cdot 2$ & $5 \cdot 6$ & $64 \cdot 4$ & $3 \cdot 4$ & $29 \cdot 7$ & $14 \cdot 6$ & $36 \cdot 4$ & $15 \cdot 1$ \\
\hline ARA $(20: 4 n-6 ; \text { mg/serving })^{*}$ & $139 \cdot 4$ & $32 \cdot 8$ & $16 \cdot 4$ & 0.8 & $75 \cdot \overline{6}$ & $10 \cdot 1$ & $71 \cdot 1$ & $4 \cdot \overline{5}$ & $60 \cdot \overline{5}$ & $3 \cdot 9$ & $87 \cdot 4$ & 3.9 & $29 \cdot 7$ & $7 \cdot 8$ & $26 \cdot 3$ & $5 \cdot 0$ \\
\hline LA $^{* \star}(18: 2 n-6 ; \text { g/serving })^{*}$ & $2 \cdot 0$ & 0.3 & $15 \cdot 3$ & 0.0 & $0 \cdot 1$ & $0 \cdot 1$ & $0 \cdot 1$ & 0.0 & 0.6 & 0.0 & 0.1 & 0.0 & $1 \cdot 7$ & $0 \cdot 1$ & $1 \cdot 2$ & 0.1 \\
\hline ALAt+ (18:3n-3; g/serving) ${ }^{*}$ & 0.3 & $0 \cdot 1$ & $2 \cdot 1$ & 0.0 & 0.00 & $0 \cdot 0$ & 0.00 & 0.0 & 0.0 & $0 \cdot 0$ & 0.0 & $0 \cdot 0$ & 0.2 & $0 \cdot 0$ & 0.2 & 0.0 \\
\hline \multicolumn{17}{|l|}{ Select PUFA profiles } \\
\hline EPA + DHAł‡ (mg/serving) & 893 & - & 106 & - & 801 & - & 750 & - & 930 & - & 666 & - & 252 & - & 292 & - \\
\hline ARA:DHA ratio & \multicolumn{2}{|c|}{$1: 5$} & \multicolumn{2}{|c|}{$1: 5$} & \multicolumn{2}{|c|}{$1: 1$} & $1:$ & & & & & & & & $1: \varsigma$ & \\
\hline$n-6: n-3$ ratio $\$ \S$ & 2 & & 7: & & $1: 4$ & & 1: & & & & & & & & 3: & \\
\hline
\end{tabular}

ARA, arachidonic acid; LA, linoleic acid; ALA, $\alpha$-linolenic acid; FDA, Food and Drug Administration.

'Serving size information as per FDA Nutrition Facts label; serving size: $82 \mathrm{~g}$ and $2.9 \mathrm{oz}$ for salad and $56 \mathrm{~g}$ and $2.0 \mathrm{oz}$ for water and oil.

tIngredients (as per FDA Nutrition Facts label): tuna (light tuna, water, vegetable broth and salt), salad dressing (water, vinegar, sugar, modified food starch, polydextrose, microcrystalline cellulose, salt, whey protein concentrate, egg yolk, xanthan gum, titanium dioxide, natural flavour, sodium benzoate and potassium sorbate (preservatives), phosphoric acid, onion powder, lactic acid, garlic powder, spice extracts, FD and C yellow (no. 6 and no. 5), celery, textured soya flour, fructose, water chestnuts, carrots, water, glucono delta lactone, dextrose, salt, onion, spices and xanthan gum.

flngredients (as per FDA Nutrition Facts label): tuna (light tuna, water, vegetable broth and salt), heat stable mayonnaise (soyabean oil, water, whole eggs, egg yolks, vinegar, salt, sugar, potassium sorbate (as a preservative), natural flavours, natural colour), celery, textured soya flour, carrots, fructose, water chestnuts, water, glucono delta lactone, dextrose, salt, onion, gum arabic or xanthan gum.

SSD obtained from the sample $(n 4)$ of each canned tuna product category.

IIEnergy $(1 \mathrm{kcal}=4 \cdot 184 \mathrm{~kJ})$ per serving as per FDA Nutrition Facts label.

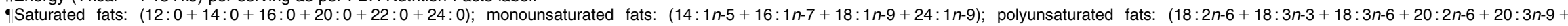
$20: 3 n-6+20: 4 n-6+20: 5 n-3+22: 6 n-3)$.

${ }^{*}$ Adequate intake for LA is between 7 and $16 \mathrm{~g}$ for children aged $\geq 4-18$ years ${ }^{(13)}$.

t+Adequate intake for ALA is between 0.9 and $1.6 \mathrm{mg}$ for children aged $4-18$ years ${ }^{(13)}$.

$¥$ EPA + DHA intakes

$\$ \S(18: 2 n-6+18: 3 n-6+20: 2 n-6+20: 3 n-6+20: 4 n-6) /(18: 3 n-3+20: 5 n-3+22: 6 n-3)$. 
Table 2 Fatty acid content of common commercially available tuna products (in $\mathrm{mg} / \mathrm{g}$ )

\begin{tabular}{|c|c|c|c|c|c|c|c|c|c|c|c|c|c|c|c|c|}
\hline \multirow{3}{*}{ Medium } & \multirow{2}{*}{\multicolumn{2}{|c|}{$\frac{\text { Fat free }}{\text { Saladt }}$}} & \multirow{2}{*}{\multicolumn{2}{|c|}{$\begin{array}{c}\text { Regular } \\
\text { Salad } \neq\end{array}$}} & \multirow{2}{*}{\multicolumn{2}{|c|}{$\frac{\text { Chunk light }}{\text { Water }}$}} & \multirow{2}{*}{\multicolumn{2}{|c|}{$\frac{\text { Chunk light }}{\text { Water }}$}} & \multirow{2}{*}{\multicolumn{2}{|c|}{$\frac{\text { Chunk white albacore }}{\text { Water }}$}} & \multirow{2}{*}{\multicolumn{2}{|c|}{$\frac{\text { Chunk white albacore }}{\text { Water }}$}} & \multirow{2}{*}{\multicolumn{2}{|c|}{$\begin{array}{c}\text { Solid white albacore } \\
\text { Oil }\end{array}$}} & \multirow{2}{*}{\multicolumn{2}{|c|}{$\frac{\text { Chunk light }}{\text { Oil }}$}} \\
\hline & & & & & & & & & & & & & & & & \\
\hline & Mean & $\mathrm{SD} \S$ & Mean & $\operatorname{SD} \S$ & Mean & $\operatorname{SD} \S$ & Mean & $\mathrm{SD} \S$ & Mean & $\mathrm{SD} \S$ & Mean & $\operatorname{SD} \S$ & Mean & $\mathrm{SD} \S$ & Mean & $\mathrm{SD} \S$ \\
\hline \multicolumn{17}{|l|}{ Fats } \\
\hline Total saturated fat & $22 \cdot 3$ & - & $50 \cdot 5$ & - & $9 \cdot 7$ & - & $9 \cdot 1$ & - & $9 \cdot 7$ & - & $7 \cdot 4$ & - & $10 \cdot 6$ & - & $9 \cdot 3$ & - \\
\hline Lauric acid $(12: 0)$ & $0 \cdot 1$ & 0.0 & 0.0 & 0.0 & $0 \cdot 0$ & 0.0 & $0 \cdot 0$ & $0 \cdot 0$ & 0.0 & 0.0 & 0.0 & $0 \cdot 0$ & 0.0 & 0.0 & $0 \cdot 0$ & 0.0 \\
\hline Myristic acid $(14: 0)$ & $0 \cdot 6$ & $0 \cdot 1$ & 0.2 & $0 \cdot 0$ & $0 \cdot 4$ & 0.0 & $0 \cdot 3$ & $0 \cdot 0$ & $0 \cdot 7$ & $0 \cdot 0$ & $0 \cdot 2$ & $0 \cdot 0$ & $0 \cdot 1$ & $0 \cdot 1$ & $0 \cdot 2$ & $0 \cdot 1$ \\
\hline Palmitic acid $(16: 0)$ & $15 \cdot 9$ & 0.5 & $34 \cdot 3$ & $0 \cdot 1$ & $6 \cdot 4$ & 0.3 & $6 \cdot 0$ & $0 \cdot 1$ & $6 \cdot 6$ & $0 \cdot 0$ & $5 \cdot 0$ & $0 \cdot 1$ & $7 \cdot 2$ & $0 \cdot 3$ & $6 \cdot 3$ & 0.7 \\
\hline Stearic acid $(18: 0)$ & $5 \cdot 1$ & 0.4 & $13 \cdot 8$ & $0 \cdot 1$ & $2 \cdot 7$ & 0.2 & $2 \cdot 4$ & 0.0 & $2 \cdot 1$ & $0 \cdot 0$ & $2 \cdot 2$ & 0.0 & $2 \cdot 8$ & $0 \cdot 1$ & $2 \cdot 6$ & $0 \cdot 1$ \\
\hline Arachidic acid $(20: 0)$ & $0 \cdot 1$ & 0.0 & 0.9 & $0 \cdot 0$ & $0 \cdot 1$ & 0.0 & $0 \cdot 1$ & $0 \cdot 0$ & $0 \cdot 1$ & $0 \cdot 0$ & $0 \cdot 0$ & 0.0 & $0 \cdot 2$ & $0 \cdot 0$ & $0 \cdot 1$ & 0.0 \\
\hline Behenic acid $(22: 0)$ & $0 \cdot 2$ & 0.0 & $1 \cdot 0$ & $0 \cdot 0$ & $0 \cdot 1$ & 0.0 & $0 \cdot 1$ & $0 \cdot 0$ & $0 \cdot 1$ & $0 \cdot 0$ & $0 \cdot 1$ & $0 \cdot 0$ & $0 \cdot 2$ & 0.0 & $0 \cdot 1$ & 0.0 \\
\hline Lignoceric acid (24:0) & 0.2 & 0.0 & 0.4 & $0 \cdot 0$ & $0 \cdot 1$ & 0.0 & $0 \cdot 1$ & $0 \cdot 0$ & $0 \cdot 1$ & 0.0 & $0 \cdot 1$ & $0 \cdot 0$ & $0 \cdot 1$ & $0 \cdot 0$ & $0 \cdot 1$ & 0.0 \\
\hline Total monounsaturated fat & $14 \cdot 8$ & - & $67 \cdot 3$ & - & $5 \cdot 0$ & - & $4 \cdot 0$ & - & $6 \cdot 2$ & - & $3 \cdot 8$ & - & $12 \cdot 2$ & - & $9 \cdot 7$ & - \\
\hline Myristoleic acid $(14: 1 n-5)$ & 0.0 & 0.0 & 0.0 & 0.0 & $0 \cdot 0$ & 0.0 & $0 \cdot 0$ & $0 \cdot 0$ & 0.0 & 0.0 & 0.0 & $0 \cdot 0$ & 0.0 & 0.0 & $0 \cdot 0$ & 0.0 \\
\hline Palmitoleic acid $(16: 1 n-7)$ & $1 \cdot 0$ & $0 \cdot 2$ & $0 \cdot 4$ & $0 \cdot 0$ & $0 \cdot 6$ & 0.0 & $0 \cdot 6$ & $0 \cdot 0$ & $1 \cdot 0$ & $0 \cdot 0$ & $0 \cdot 3$ & 0.0 & $0 \cdot 2$ & $0 \cdot 2$ & $0 \cdot 3$ & 0.2 \\
\hline Oleic acid $(18: 1 n-9)$ & $13 \cdot 4$ & 0.5 & $66 \cdot 9$ & $0 \cdot 0$ & $4 \cdot 0$ & 0.4 & $3 \cdot 0$ & $0 \cdot 0$ & $4 \cdot 8$ & $0 \cdot 2$ & $3 \cdot 0$ & $0 \cdot 2$ & $11 \cdot \overline{9}$ & $0 . \overline{2}$ & $9 \cdot 3$ & 0.4 \\
\hline Nervonic acid $(24: 1 n-9)$ & $0 \cdot 4$ & $0 \cdot 1$ & $0 \cdot 1$ & $0 \cdot 0$ & $0 \cdot 4$ & $0 \cdot 1$ & $0 \cdot 4$ & $0 \cdot 0$ & 0.5 & $0 \cdot 0$ & $0 \cdot 6$ & $0 \cdot 0$ & $0 \cdot 2$ & $0 \cdot 1$ & $0 \cdot 2$ & $0 \cdot 0$ \\
\hline Total polyunsaturated fat (mean) & $41 \cdot 0$ & - & $213 \cdot 2$ & - & $15 \cdot 8$ & - & $16 \cdot 1$ & - & $19 \cdot 2$ & - & $15 \cdot 7$ & - & $39 \cdot 2$ & - & $30 \cdot 9$ & - \\
\hline LA $(18: 2 n-6)$ & $24 \cdot 9$ & $3 \cdot 7$ & $186 \cdot 4$ & $0 \cdot 1$ & $2 \cdot 1$ & $1 \cdot 2$ & $1 \cdot 1$ & $0 \cdot 4$ & $1 \cdot 1$ & $0 \cdot 4$ & $2 \cdot 0$ & $0 \cdot 1$ & $30 \cdot 3$ & $1 \cdot 3$ & $22 \cdot 2$ & $2 \cdot 3$ \\
\hline$\gamma$-Linolenic acid $(18: 3 n-6)$ & 0.0 & 0.0 & 0.0 & $0 \cdot 0$ & $0 \cdot 0$ & 0.0 & $0 \cdot 0$ & $0 \cdot 0$ & 0.0 & 0.0 & $0 \cdot 0$ & $0 \cdot 0$ & $0 \cdot 0$ & $0 \cdot 0$ & 0.0 & 0.0 \\
\hline ÁAA $(18: 3 n-3)$ & $3 \cdot 2$ & 0.6 & $25 \cdot 0$ & $0 \cdot 2$ & $0 \cdot 3$ & 0.2 & $0 \cdot 2$ & $0 \cdot 1$ & 0.2 & $0 \cdot 1$ & $0 \cdot 2$ & $0 \cdot 0$ & $3 \cdot 8$ & $0 \cdot 1$ & $3 \cdot 0$ & $0 \cdot 3$ \\
\hline Icosadienoic acid $(20: 2 n-6)$ & $0 \cdot 1$ & 0.0 & $0 \cdot 1$ & $0 \cdot \overline{0}$ & $0 \cdot 1$ & 0.0 & $0 \cdot 1$ & $0 \cdot 0$ & $0 \cdot 1$ & $0 \cdot 0$ & $0 \cdot 1$ & $0 \cdot 0$ & $0 \cdot 1$ & $0 \cdot 0$ & $0 \cdot 0$ & $0 \cdot 0$ \\
\hline Mead acid $(20: 3 n-9)$ & $0 \cdot 0$ & 0.0 & 0.0 & $0 \cdot 0$ & $0 \cdot 0$ & 0.0 & $0 \cdot 0$ & $0 \cdot 0$ & 0.0 & $0 \cdot 0$ & $0 \cdot 0$ & 0.0 & $0 \cdot 0$ & $0 \cdot 0$ & $0 \cdot 0$ & 0.0 \\
\hline Dihomo- $\gamma$-linolenic acid $(20: 3 n-6)$ & $0 \cdot 1$ & 0.0 & $0 \cdot 1$ & $0 \cdot 0$ & $0 \cdot 0$ & 0.0 & $0 \cdot 0$ & $0 \cdot 0$ & 0.0 & $0 \cdot 0$ & $0 \cdot 0$ & $0 \cdot 0$ & $0 \cdot 0$ & $0 \cdot 0$ & $0 \cdot 1$ & $0 \cdot 0$ \\
\hline ARA $(20: 4 n-6)$ & $1 \cdot 7$ & 0.4 & $0 \cdot 2$ & $0 \cdot 0$ & $1 \cdot 4$ & 0.2 & $1 \cdot 3$ & $0 \cdot 1$ & $1 \cdot 1$ & $0 \cdot 1$ & $1 \cdot 6$ & $0 \cdot 1$ & 0.5 & $0 \cdot 1$ & 0.5 & $0 \cdot 1$ \\
\hline EPA $(20: 5 n-3)$ & $1 \cdot 5$ & 0.4 & 0.2 & 0.01 & $1 \cdot 7$ & 0.2 & $1 \cdot 7$ & $0 \cdot 0$ & $3 \cdot 0$ & $0 \cdot 1$ & $1 \cdot 2$ & $0 \cdot 1$ & $0 \cdot 5$ & $0 \cdot 3$ & $0 \cdot 7$ & $0 \cdot 3$ \\
\hline DHA (22:6n-3) & $9 \cdot 5$ & $2 \cdot 2$ & $1 \cdot 1$ & $0 \cdot 1$ & $12 \cdot 6$ & $1 \cdot 1$ & $11 \cdot 7$ & 0.4 & $13 \cdot 6$ & 0.2 & $10 \cdot 7$ & 0.3 & 4 & $0 \cdot 8$ & $4 \cdot 6$ & $1 \cdot 6$ \\
\hline
\end{tabular}

LA, linoleic acid; ARA, arachidonic acid; ALA, $\alpha$-linolenic acid; FDA, Food and Drug Administration.

*Serving size: $82 \mathrm{~g}$ for salad and $56 \mathrm{~g}$ for water and oil.

+Ingredients (as per FDA Nutrition Facts label): tuna (light tuna, water, vegetable broth and salt), salad dressing (water, vinegar, sugar, modified food starch, polydextrose, microcrystalline cellulose, salt, whey protein concentrate, egg yolk, xanthan gum, titanium dioxide, natural flavour, sodium benzoate and potassium sorbate (preservatives), phosphoric acid, onion powder, lactic acid, garlic powder, spice extracts, FD and C yellow (nother, salt, onion, spices, xanthan gum.

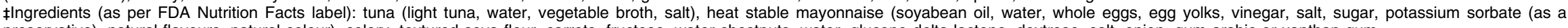
soya flour, carrots, fructose, water chestnuts, water, glucono delta lactone, dextrose, salt, onion, gum arabic or xanthan gum.

§SD obtained from sample of $(n 4)$ each canned tuna product category. 
free-range or wild counterparts, with data from studies in cattle and salmon serving as an excellent example ${ }^{(8-10)}$. Processing and packaging of food products also alter total fat and FA profiles of foods; a recent study has shown more than a fifty-fold change in the $n-6: n-3$ ratio during food processing ${ }^{(7)}$.

There are commercial supplier and consumer factors that influence the changes that occur in nutrient content from tuna, between the time it is captured and when it is purchased as a commercial tuna product. Tuna PUFA content varies by species; canned tuna is a 'product' and individual canned products may contain more than one species of tuna. The nomenclature used to describe tuna products includes 'white tuna', which refers to albacore and northern and southern bluefin tuna species; and 'light tuna', which includes skipjack (the most common), yellowfin and bigeye tuna species ${ }^{(23)}$. Although distinct differences in PUFA profiles were noted across the range of products in the present study, some of the differences between similar products may have been related to differences in the tuna species present in individual cans. Consumer choices also influence the tuna products that are commercially made available and promoted. Packaging of tuna products in vegetable oil to diminish the fishy odour and enhance palatability is a good example of consumer-driven modification. Similarly, tuna salad products enhance consumer convenience. Some of these modifications, such as packaging in vegetable oils and in salads, alter the energy content and the DHA, EPA and LA contents $^{(24)}$. Mayonnaise is a good source of ALA and the tuna salad product had the greatest ALA content per serving among the tested products; mayonnaise was the second major ingredient listed on the Nutrition Facts label (after tuna). This provides insight into some of the changes in nutrient content that occur between capture and eventual consumption. The data we present in the present study provide complete FA profiles of the tested products to allow for comparison.

Consumption of marine life also has associated health risks for humans that have to be considered. Fatty fish may be contaminated with methyl mercury, polychlorinated biphenyls and dioxans. These are linked to adverse health risks that may offset some of the benefits of $n-3$ PUFA and result in more complex dietary counselling for children and women who are either pregnant or planning to be pregnant ${ }^{(10,25,26)}$. The FDA currently recommends a dietary intake of up to $12 \mathrm{oz}$ of fish per week. Although albacore tuna has the highest DHA content of all tuna species, it also has more methyl mercury than other tuna and the FDA recommends no more than $6 \mathrm{oz}$ albacore/week. Furthermore, women of childbearing age and children under the age of 5 years are advised not to consume albacore tuna. If more than one type of fish is consumed regularly, the total amount of fish per week may need to be reduced in order to limit mercury intake ${ }^{(6,27,28)}$. Although tuna contaminant content was not assessed in the present study, findings from the literature suggest that chunk light tuna in water has relatively lower mercury content than other tuna products ${ }^{(29,30)}$, and as this product provides relatively high $n-3$ PUFA (DHA + EPA) content, a lower $n-6: n-3$ ratio, these findings suggest that chunk light tuna in water may be the better choice of tuna product for the healthy population.

Another dimension in the consideration of tuna products from a health benefit perspective is with respect to special populations or groups who may be at risk for EFA deficiency and PUFA abnormalities, such as children with cystic fibrosis; the most common PUFA abnormalities reported in these children are low LA and DHA status ${ }^{(31,32)}$. For these children, tuna canned in oil may be preferable in order to provide both LA and DHA.

PUFA intake needs to be considered in two important ways: to ensure EFA adequacy and prevent deficiency (particularly in at-risk populations) and to reduce primary and secondary disease risk by promoting $n-3$ PUFA intake. The tuna data presented here can support dietary counselling for our patients and for consumers in making informed decisions in the context of practical strategies to promote improved dietary intake of $n$ - 3 FA and decrease the $n-6: n-3$ ratio $^{(31,32)}$. Substitution of cooking oils with more favourable ALA content and PUFA profiles (such as walnut and rapeseed oils) and the use of $n$ - 3 -fortified foods also support healthy fat intake. Increased awareness regarding these considerations may lead consumers to favour foods richer in $n$-3 PUFA and lower in contaminants and may also influence animal-rearing practices and effect change in the food supply.

\section{Conclusions}

We provide information on the variability of PUFA profiles and $n-3$ FA across tuna products to support consumer choices and health education useful in promoting healthier diets. Tuna products are a good source of DHA and EPA with favourable PUFA profiles, and our data suggest that among these products light canned tuna packaged in water may be a better choice for children and adults to increase their $n$-3 PUFA intake.

\section{Acknowledgements}

The present study was supported by the National Heart, Lung and Blood Institute of the US National Institutes of Health (R01HL57448), the Clinical Translational Research Center (UL RR 0241340), the Nutrition Center at the Children's Hospital of Philadelphia, the Cystic Fibrosis Foundation, the Medical Faculty of the University of Gothenburg for the analyses of fatty acids and the Erica Lederhausen Foundation. The authors have no conflict of interest to declare. A.M. obtained the commercial tuna products for analyses; B.S. performed the fatty acid analyses. 
All three authors conceived the study, contributed to the statistical analyses, to the writing of the manuscript and have read and approved the manuscript. The authors thank Berit Holmberg for technical assistance in the PUFA analyses.

\section{References}

1. Simopoulos AP (1999) Essential fatty acids in health and chronic disease. Am J Clin Nutr 70, Suppl. 3, 560S-569S.

2. Simopoulos AP (2008) The importance of the omega-6/ omega-3 fatty acid ratio in cardiovascular disease and other chronic diseases. Exp Biol Med (Maywood) 233, 674-688.

3. Kris-Etherton PM, Harris WS \& Appel LJ (2003) Omega-3 fatty acids and cardiovascular disease: new recommendations from the American Heart Association. Arterioscler Thromb Vasc Biol 23, 151-152.

4. Ailhaud G, Massiera F, Weill P et al. (2006) Temporal changes in dietary fats: role of $n-6$ polyunsaturated fatty acids in excessive adipose tissue development and relationship to obesity. Prog Lipid Res 45, 203-236.

5. Calder PC (2003) n-3 Polyunsaturated fatty acids and inflammation: from molecular biology to the clinic. Lipids 38, 343-352.

6. Environmental Protection Agency (2009) Estimated per capita fish consumption in the United States. http://www. epa.gov/waterscience/fish/files/consumption_report/pdf (accessed January 2010).

7. Sampels S, Strandvik B \& Pickova J (2009) Processed animal products with emphasis on polyunsaturated fatty acid content. Eur J Lipid Sci Technol 111, 481-488.

8. Mandell IB, Buchanan-Smith JG \& Campbell CP (1998) Effects of forage vs grain feeding on carcass characteristics, fatty acid composition, and beef quality in Limousin-cross steers when time on feed is controlled. J Anim Sci 76, 2619-2630.

9. Kitessa SM, Gulati SK, Simos GC et al. (2004) Supplementation of grazing dairy cows with rumen-protected tuna oil enriches milk fat with $n-3$ fatty acids without affecting milk production or sensory characteristics. Br J Nutr 91, 271-278.

10. Hamilton MC, Hites RA, Schwager SJ et al. (2005) Lipid composition and contaminants in farmed and wild salmon. Environ Sci Technol 39, 8622-8629.

11. Stubbs CD, Kinosita K Jr, Munkonge F et al. (1984) The dynamics of lipid motion in sarcoplasmic reticulum membranes determined by steady-state and time-resolved fluorescence measurements on 1,6-diphenyl-1,3,5-hexatriene and related molecules. Biochim Biophys Acta $\mathbf{7 7 5}$, 374-380.

12. Clarke SD (2004) The multi-dimensional regulation of gene expression by fatty acids: polyunsaturated fats as nutrient sensors. Curr Opin Lipidol 15, 13-18.

13. Institute of Medicine (2005) Dietary Reference Intakes for Energy, Carbohydrate, Fiber, Fat, Fatty Acids, Cholesterol, Protein, and Amino Acids (Macronutrients). Washington, DC: National Academy Press.

14. Bjerve KS, Fischer S \& Alme K (1987) Alpha-linolenic acid deficiency in man: effect of ethyl linolenate on plasma and erythrocyte fatty acid composition and biosynthesis of prostanoids. Am J Clin Nutr 46, 570-576.

15. Plourde M \& Cunnane SC (2007) Extremely limited synthesis of long chain polyunsaturates in adults: implications for their dietary essentiality and use as supplements. Appl Physiol Nutr Metab 32, 619-634.

16. Brenna JT, Salem N Jr, Sinclair AJ et al. (2009) Alphalinolenic acid supplementation and conversion to $n$-3 longchain polyunsaturated fatty acids in humans. Prostaglandins Leukot Essent Fatty Acids 80, 85-91.

17. Shoda R, Matsueda K, Yamato S et al. (1996) Epidemiologic analysis of Crohn disease in Japan: increased dietary intake of $n-6$ polyunsaturated fatty acids and animal protein relates to the increased incidence of Crohn's disease in Japan. Am J Clin Nutr 63, 741-745.

18. Dewailly E, Blanchet C, Lemieux S et al. (2001) n-3 Fatty acids and cardiovascular disease risk factors among the Inuit of Nunavik. Am J Clin Nutr 74, 464-473.

19. Griffin B (2008) How relevant is the ratio of dietary $n-6$ to $n-3$ polyunsaturated fatty acids to cardiovascular disease risk? Evidence from the OPTILIP study. Curr Opin Lipidol 19, 57-62.

20. Koletzko B, Cetin I \& Brenna JT (2007) Dietary fat intakes for pregnant and lactating women. Br J Nutr 98, 873-877.

21. Koletzko B, Lien E, Agostoni C et al. (2008) The roles of long-chain polyunsaturated fatty acids in pregnancy, lactation and infancy: review of current knowledge and consensus recommendations. J Perinat Med 36, 5-14.

22. Harris WS, Mozaffarian D, Lefevre M et al. (2009) Towards establishing dietary reference intakes for eicosapentaenoic and docosahexaenoic acids. J Nutr 139, issue 4, 804S-819S.

23. US Tuna Foundation (2010) HealthyTuna.com. http:// www.healthytuna.com/about-tuna/tuna-species (accessed January 2010).

24. Shim SM, Dorworth LE, Lasrado JE et al. (2004) Mercury and fatty acids in canned tuna, salmon, and mackerel. J Food Sci 69, C681-C684.

25. Foran JA, Good DH, Carpenter DO et al. (2005) Quantitative analysis of the benefits and risks of consuming farmed and wild salmon. J Nutr 135, 2639-2643.

26. Guallar E, Sanz-Gallardo MI, van't Veer P et al. (2002) Mercury, fish oils, and the risk of myocardial infarction. $N$ Engl J Med 347, 1747-1754.

27. Environmental Protection Agency of the Food and Drug Administration (2004) What you need to know about mercury in fish and shellfish. http://www.fns.usda.gov/ fdd/facts/nutrition/fishfacts.pdf (accessed January 2010).

28. Food and Nutrition Board, Institute of Medicine (2007) Seafood Choices: Balancing Benefits and Risks. Washington, DC: National Academy Press.

29. Burger J \& Gochfeld M (2004) Mercury in canned tuna: white versus light and temporal variation. Environ Res $\mathbf{9 6}$, 239-249.

30. Yess NJ (1993) US food and drug administration survey of methyl mercury in canned tuna. J AOAC Int 76, 36-38.

31. Coste TC, Armand M, Lebacq J et al. (2007) An overview of monitoring and supplementation of omega 3 fatty acids in cystic fibrosis. Clin Biochem 40, 511-520.

32. Cawood AL, Carroll MP, Wootton SA et al. (2005) Is there a case for $n-3$ fatty acid supplementation in cystic fibrosis? Curr Opin Clin Nutr Metab Care 8, 153-159. 